\title{
PK-PD interaction study of angiotensin Il antagonist, losartan, with selective estrogen receptor modulator, centchroman
}

\begin{abstract}
Aim: The effect on pharmacokinetics and postcoital contraceptive efficacy of centchroman was investigated after concomitant administration of losartan. Materials \& methods: An LC-MS/MS method was employed for quantification of centchroman in blood of female rats treated with centchroman $(1.5 \mathrm{mg} / \mathrm{kg})$ only and centchroman plus losartan ( $5 \mathrm{mg} / \mathrm{kg}$, once daily up to day 7 ). The effect of losartan on the postcoital contraceptive activity of centchroman was evaluated in sperm-positive female rats. Results: The area under the curve and mean residence time values were decreased in losartan concomitant group, however, sperm-positive female rats did not exhibit any implantations in either centchroman only or losartan co-administered group of female rats. Conclusion: The study evidenced no pharmacological interaction of losartan with centchroman.
\end{abstract}

Keywords: DBS • drug interaction $\bullet$ LC-MS/MS • losartan • ormeloxifene

Centchroman (INN: ormeloxifene) is a selective estrogen receptor modulator once-aweek nonsteroidal female oral contraceptive. Since 1991, it has been marketed with different trade names (Saheli, Novex, Novex-DS and Sevista) and almost 25,000,000 doses are being sold per year for contraception $[1,2]$. Centchroman, a nonhormonal contraceptive, has an excellent therapeutic index and reported useful for various hormone-related disorders such as breast cancer, ovarian cancer, premenopausal dysfunctional uterine bleeding, postmenopausal osteoporosis, atherogenicity, dermatitis, fibroadenomas, menorrhagia, restenosis, mastalgia, male infertility and ovulation induction in the amenorrheic women [3-6]. Following a single oral dose of $30 \mathrm{mg}$ and $60 \mathrm{mg}$ of centchroman to adult female volunteers, the maximum serum concentration $\left(\mathrm{C}_{\max }\right)$ ranged from 30.5 to 78.4 and 117 to $129 \mathrm{ng} / \mathrm{ml}$, which occurred $\left(\mathrm{t}_{\max }\right)$ from 3 to 8 and $4 \mathrm{~h}$, respectively [7]. Centchroman is metabolized through both Phase I and Phase II enzymes. Seven metabolites of centchroman have been reported in an in vitro metabolism study using rat liver homogenate [8]. An active metabolite, 7-desmethyl centchroman, exhibits 20-fold cytosol receptor binding affinity and equivalent anti-implantation activity to the centchroman. The CYP reaction phenotyping of centchroman is not available in the literature. It was quantified in serum and milk samples and metabolite to parent drug ratio was independent of dosage regimen [9].

Contraceptives are commonly recommended for long periods for adult females, up to their desire to plan a baby or relocate to a permanent birth control method, meanwhile many of these may need to have another concomitant medication for the management of intercurrent pathological condition. Hypertension is among the most common cardiometabolic disorders, now prevalent in young age due to bad dietary habits and obesity. A study conducted among the young adult female students of Dammam, Saudi Arabia revealed that $13.5 \%$ of the students were prehypertensive [10]. Chaudhry et al. divulged that $58 \%$ of young females of age 18-25 years were diagnosed with prehypertension in Wardha, India [11]. Another clinical study
Abhisheak Sharma ${ }^{\dagger, 1,2}$, Swati Jaiswal ${ }^{1,2}$, Mahendra Shukla ${ }^{1,2}$, Jitendra Kumar Singh ${ }^{3}$, Ganesh Haranadh Narisipuram ${ }^{3}$ \& Jawahar Lal ${ }^{*}, 1,2$

'Pharmacokinetics \& Metabolism Division, CSIR-Central Drug Research Institute, Jankipuram Extension, Sitapur Road, Lucknow, 226031, India ${ }^{2}$ Academy of Scientific \& Innovative Research, New Delhi, India ${ }^{3}$ Department of Pharmaceutics, National Institute of Pharmaceutical Education \& Research (NIPER), Raebareli, 229010, India

*Author for correspondence:

Tel.: +91522 2772474

Fax: +91522 2771941

j_lal@cdri.res.in

${ }^{+}$Current affiliation: Department of Pharmaceutics \& Drug Delivery, The University of Mississippi, Mississippi 38677, USA 
directed by Lloyds pharmacy in the UK reported that $35 \%$ of the young volunteers (age less than 34 years) were diagnosed with symptoms of mild to very severe hypertension [11,12]. The increment in the number of female hypertensive patients in childbearing age requires adequate information to find out choice of medication in spite of drug-drug interaction between antihypertensive drugs with other concomitant drug. Losartan, an angiotensin II receptor antagonist, is a choice of drug for long-term treatment of hypertension with greater persistence rate than treatment with any other antihypertensive drug [13]. Treatment with losartan is well tolerated with the required reduction in blood pressure and it reduces the cardiovascular morbidity and death of hypertensive patients [14]. It exhibits rapid oral absorption and its $\mathrm{C}_{\max }$ reached within the $1-2 \mathrm{~h}$ postdose. Losartan converted into its carboxylic acid metabolite (E 3174) by cytochromes and the active metabolite is 10 - to 40 -fold more potent than losartan [15]. Losartan is a drug of choice for the treatment of hypertension and intended for long-term use. In view of this, we considered it appropriate to study centchroman, another long-term used drug, along with losartan to explore the possibility of pharmacokinetic and pharmacodynamic (PK-PD) interaction, if any. This can help physicians to confer in the selection of concomitant medication without compromising the reproductive goals of the hypertensive females.

\section{Methods}

Materials \& reagents

Centchroman as centchroman hydrochloride (purity $=99.8 \%$; IP grade) was provided as gratis sample by HLL Lifecare (Thiruvananthapuram, India) and 7-desmethyl centchroman (7-DMC) as free base (purity $>99.1 \%$ ) was synthesized in-house [16]. Losar$\tan$ as losartan potassium and raloxifene as raloxifene $\mathrm{HCl}$ (internal standard [IS]) were purchased from Sigma Aldrich (Frankfurt, Germany). HPLC-grade acetonitrile (ACN) was purchased from Sigma Aldrich (Dombivli, India). HPLC-grade $n$-hexane, ethyl acetate and analytical grade ammonium acetate were purchased from Spectrochem Pvt. Ltd. (Mumbai, India). Ultrapure water (18.2 $\Omega \mathrm{M}$ ) was from a Milli-Q PLUS PF (Billerica, MA, USA). Heparin sodium injection $(5000 \mathrm{IU} / \mathrm{ml})$ was purchased from Biocon (Bangalore, India). Drug-free whole blood was collected from adult and healthy female Sprague Dawley rats. FTA classic cards were purchased from Whatman (Maidstone, UK).

\section{Animals}

Young adult female Sprague Dawley rats (10-12 weeks old, weighing $225 \pm 20 \mathrm{~g}$ ) maintained under standard in-house conditions (room temperature $\left[24 \pm 2^{\circ} \mathrm{C}\right]$, relative humidity [40-60\%] and a 12-h light-dark cycle) were procured from the National Laboratory Animal Center, CDRI (Lucknow, India). They were given a standard pellet diet (Lipton India Ltd., Bangalore) and tap water ad libitum. Prior to the experiments, animals were acclimatized for at least 1 week. All experiments, euthanasia and disposal of carcasses were carried out as per the guidelines and the study protocols submitted to the local ethics committee for animal experimentation.

\section{Pharmacokinetic interaction study}

Overnight fasted (14-16 h; free access to water) adult female Sprague Dawley rats were divided into two groups $(n=4$, each): centchroman only and centchroman with losartan. The rat dose of centchroman and losartan was calculated from the standard clinical human dose using equation; rat dose $=([$ human dose $/$ average body weight] ${ }^{*}$ 7) [17]. Centchroman and losartan were suitably formulated (Table 1) as solutions. In the present study, each group of rats received a single $1.5 \mathrm{mg} / \mathrm{kg}$ per oral dose of centchroman with or without losartan ( $5 \mathrm{mg} / \mathrm{kg}$, once daily up to day 7$)$. The aqueous solution formulation of losartan was administered at an intervening period of $10 \mathrm{~min}$ after the centchroman dose and was given up to day 6 (once a day) as per the dosing schedule of losartan. Blood samples $(\approx 80 \mu \mathrm{l})$ were carefully collected from the caudal vein into preheparinized microcentrifuge tubes (Axygen, CA, USA) at $0.5,1.0,2,4,6,8,12,24,48,96,120$, 144 and $168 \mathrm{~h}$ postdose from each rat. Out of the sampled blood, $30 \mu \mathrm{l}$ of blood sample was spotted on FTA classic cards. The dried blood spots (DBS) were duly labeled, allowed to dry overnight at room temperature and stored in a desiccator containing calcium chloride until analysis.

\section{LC-MS/MS analysis of centchroman \& 7-DMC}

A DBS-based LC-MS/MS method was developed for quantification of centchroman and its active metabolite (7-DMC) over a calibration range of $0.25-200$ $\mathrm{ng} / \mathrm{ml}$ for both the analytes. In brief, a simple liquidliquid extraction method was used for extraction of the analytes from DBS by $2 \times 2 \mathrm{ml}$ extraction solvent ( $40 \%$ ethyl acetate in $\mathrm{n}-$ Hexane, $\mathrm{v} / \mathrm{v}$ ) after addition of $10 \mu \mathrm{l}$ of IS $(1250 \mathrm{ng} / \mathrm{ml})$. After vortexing for $20 \mathrm{~min}$, it was centrifuged at $3000 \mathrm{rpm}$ for $10 \mathrm{~min}$ followed by separation of organic layer $(1.6 \mathrm{ml})$. The organic extractive was evaporated to dryness in Speed Vac Concentrator (Savant Instrument, Farmingdale, NY, USA). The residue was reconstituted with $100 \mu \mathrm{l}$ of the mobile phase and $20 \mu \mathrm{l}$ was injected into LC-MS/ MS system for analysis. 
Table 1. Dosing schedule and formulation for centchroman and losartan and the effect of losartan on the postcoital anti-implantation activity of centchroman.

\begin{tabular}{|c|c|c|c|c|c|}
\hline Group & Treatment & Formulation and dosing schedule & $\begin{array}{l}\text { Pregnant/ } \\
\text { treated rats }\end{array}$ & $\begin{array}{l}\text { Corpora } \\
\text { lutea* }\end{array}$ & Implantations* \\
\hline 1 & Vehicle only & $\begin{array}{l}\text { Solution }(20 \% \mathrm{v} / \mathrm{v} \text { ethanol in triple } \\
\text { distilled water }) \text {, single dose on day } 1 \\
\text { pc }(0.5 \mathrm{ml} / \mathrm{kg}, \mathrm{po})\end{array}$ & $6 / 6$ & 63 & 60 \\
\hline II & $\begin{array}{l}\text { Centchroman } \\
\text { only }\end{array}$ & $\begin{array}{l}\text { Solution ( } 1.5 \mathrm{mg} \text { free drug in } 4 \mathrm{ml} \\
20 \% \mathrm{v} / \mathrm{v} \text { ethanol in triple distilled } \\
\text { water), single dose on day } 1 \mathrm{pc}(1.5 \\
\mathrm{mg} / \mathrm{kg}, \mathrm{po})\end{array}$ & $0 / 6$ & 51 & 0 \\
\hline III & $\begin{array}{l}\text { Centchroman + } \\
\text { losartan }\end{array}$ & $\begin{array}{l}\text { Centchroman, solution ( } 1.5 \mathrm{mg} \text { free } \\
\text { drug in } 4 \mathrm{ml} 20 \% \text { v/v ethanol in triple } \\
\text { distilled water), single } 1.5 \mathrm{mg} / \mathrm{kg} \text { per } \\
\text { oral on day } 1 \mathrm{pc} \text { ) + losartan, solution } \\
(5 \mathrm{mg} \text { losartan potassium in } 4 \mathrm{ml} \\
\text { triple distilled water), } 5 \mathrm{mg} / \mathrm{kg} \mathrm{per} \\
\text { oral once daily on days } 1-7 \mathrm{pc} \text { ) }\end{array}$ & $0 / 6$ & 54 & 0 \\
\hline IV & Losartan only & $\begin{array}{l}\text { Losartan, solution ( } 5 \mathrm{mg} \text { losartan } \\
\text { potassium in } 4 \mathrm{ml} \text { triple distilled } \\
\text { water), } 5 \mathrm{mg} / \mathrm{kg} \text { per oral once daily on } \\
\text { days } 1-7 \mathrm{pc} \text { ) }\end{array}$ & $6 / 6$ & 57 & 52 \\
\hline
\end{tabular}

A UFLC system (Shimadzu, Kyoto, Japan) coupled with hybrid triple quadrupole mass spectrometer (4000 Q Trap, Applied Biosystems, Toronto, Canada) was applied for quantitative analysis of the study samples. Chromatographic separations were achieved on a Discovery HS C-18 column $\left(50^{*} 4.6 \mathrm{~mm}, 5 \mu \mathrm{m}\right.$; Supelco Analytical, Bellefonte, USA) preceded by a guard column packed with the same material using mobile phase (ACN: $0.01 \mathrm{M}$ aqueous ammonium acetate buffer $[A A B], 85: 15, \mathrm{v} / \mathrm{v}$ at a flow rate of 0.8 $\mathrm{ml} / \mathrm{min}$ ). Multiple reaction monitoring (MRM) with ESI on positive mode (ion spray voltage, $5500 \mathrm{~V}$ ) was utilized to perform mass spectrometric quantification on the transitions $m / z 458.6 \rightarrow 98.2$ for centchroman, $\mathrm{m} / \mathrm{z} 444.2 \rightarrow 98.2$ for 7 -DMC and $\mathrm{m} / \mathrm{z} 472.2 \rightarrow 112.2$ for IS. Source parameters, namely curtain gas, nebulizer gas and heater gas, were set at 15, 50 and 45 psi, respectively. The method was validated for the linearity range of $0.25-200 \mathrm{ng} / \mathrm{ml}$ for both the analytes. Quality control (QC) samples at the concentration levels $0.25 \mathrm{ng} / \mathrm{ml}$ (LLOQ), $1 \mathrm{ng} / \mathrm{ml}$ (LQC), $90 \mathrm{ng} / \mathrm{ml}$ (MQC) and $180 \mathrm{ng} / \mathrm{ml}$ (HQC) were prepared separately in replicates $(n=6$, each), independent of the calibration standards for both centchroman and 7-DMC. Test samples and quality control samples were interpolated from the calibration curve to obtain the concentrations of the respective analytes.

\section{Pharmacokinetics analysis}

The observed $\mathrm{C}_{\max }$ and $\mathrm{t}_{\max }$ were obtained directly from visual inspection of concentration-time profile. Due to the occurrence of multiple peaks, dried blood spot concentration data were subjected to noncompartmental approach using Phoenix WinNonlin (version 6.3; Certara, Inc., MO, USA) to quantify the pharmacokinetic parameters, namely, $\mathrm{AUC}_{\text {last }}=$ area under the blood concentration-time curve upto $168 \mathrm{~h}, \mathrm{t}_{1 / 2}=$ elimination half-life, $\mathrm{Cl} / \mathrm{F}$ = clearance, $\mathrm{V}_{\mathrm{d}} / \mathrm{F}=$ volume of distribution and $\mathrm{MRT}=$ mean residence time. The relative bioavailability of centchroman was calculated by the equation, percent relative bioavailability $=\left(\mathrm{AUC}_{\text {losartan }}\right.$ co-administered group $*$ Dose of centchroman cent only group $_{\text {/AUC- }}$ cent only ${ }^{*}$ Dose of centchroman $\left.n_{\text {losartan co-administered group }}\right) * 100$.

\section{Statistical analysis}

The data are presented as mean \pm SEM. For evaluation of the effect of losartan on the pharmacokinetics profile of centchroman the pharmacokinetics parameters $\left(\mathrm{C}_{\text {max }}, \mathrm{t}_{\text {max }}, \mathrm{AUC}_{\text {last }}, \mathrm{t}_{1 / 2}, \mathrm{Cl} / \mathrm{F}, \mathrm{V}_{\mathrm{d}} / \mathrm{F}\right.$ and MRT $)$ were subjected to Student's t-test using GraphPad Prism (version 5.01; GraphPad Software, Inc., CA, USA). The pharmacokinetic parameters between the centchroman only and losartan co-administered group of rats were considered to be statistically significantly different on comparison using the probability of the null hypothesis at $\mathrm{p}$ value of $<0.05$. 


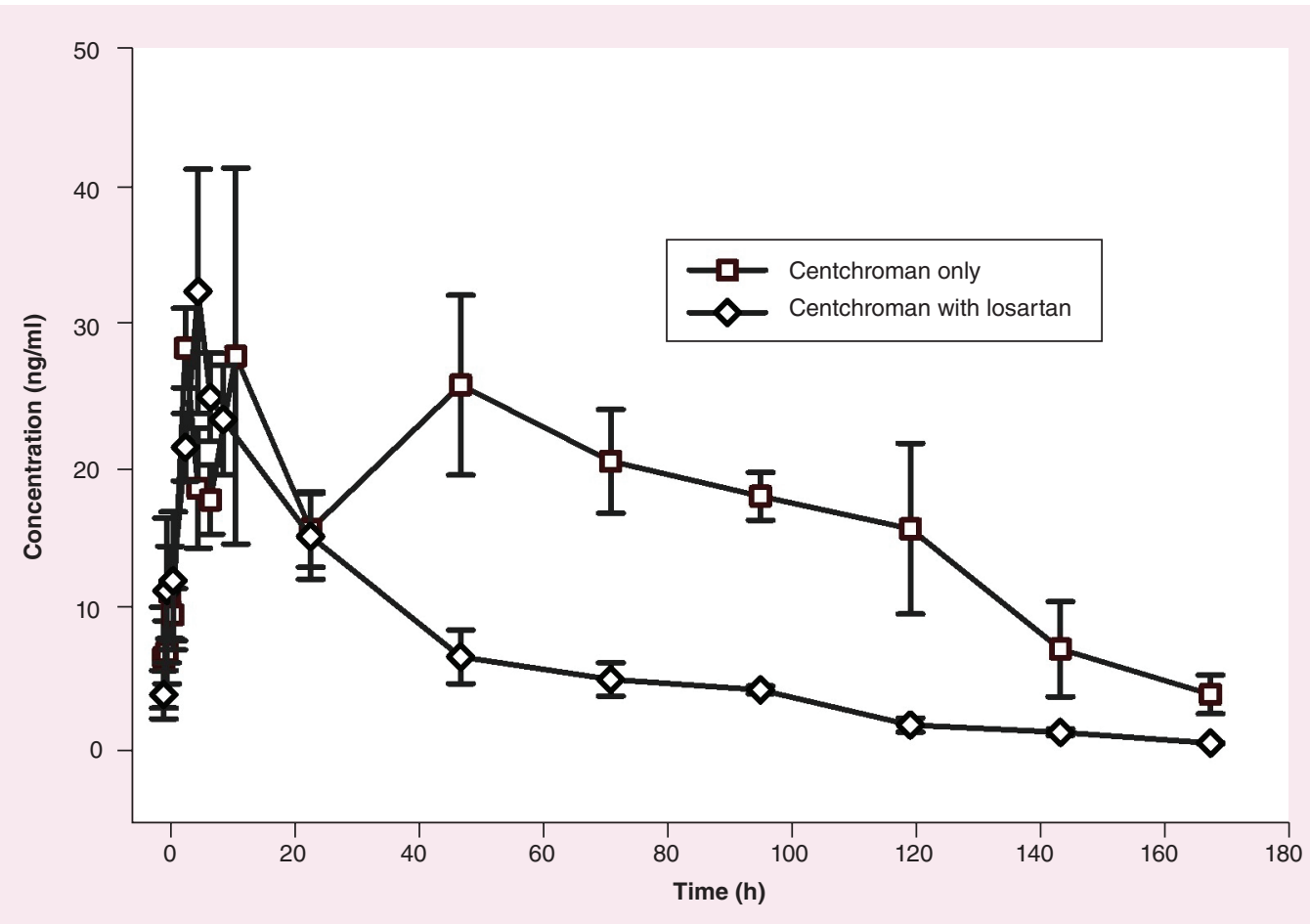

Figure 1. Mean blood concentration-time profile of centchroman in female rats treated with centchroman alone and with losartan in female Sprague Dawley rats $(n=4)$. Bar represents SEM.

Pharmacodynamic interaction

After finding the significant variations in pharmacokinetic parameters $\left(\mathrm{AUC}_{\text {lass }}, \mathrm{Cl} / \mathrm{F}, \mathrm{MRT}\right.$ and $\left.\mathrm{V}_{\mathrm{d}} / \mathrm{F}\right)$ of centchroman in losartan co-administered group of rats, the consequences on postcoital contraceptive efficacy of centchroman were studied. The proven fertile males were co-caged in a ratio of 1:3 with proestrous female Sprague Dawley rats of 4- or 5-day estrous cycles. The co-habited female rats were examined on the next morning for copulatory plug and the presence of spermatozoa in their vaginal smears by microscopic examination (Carl Zeiss, Gottingen, Germany). The sperm-positive female rats were isolated and divided in four groups viz., vehicle, centchroman only, centchroman and losartan or the losartan only. As shown in Table 1, centchroman was administered as a single $1.5 \mathrm{mg} / \mathrm{kg}$ per oral dose on day 1 postcoitum (pc), while the losartan was administered up to day $7(5 \mathrm{mg} / \mathrm{kg}$, once daily up to day 7) with an intervening period of $\sim 10 \mathrm{~min}$. On the 10th day pc, the status of the uterus was examined for the presence (normal conceptuses or resorbing) or absence of implantation sites. The status and total number of corpora lutea on both sides of ovary and body weight were noted.

\section{Results}

LC-MS/MS analysis of centchroman \& 7-DMC in DBS

A DBS-based liquid chromatography tandem mass spectrometric method was validated following the
US FDA Bioanalytical Method Validation Guidance for validation parameters, namely, accuracy, precision, specificity, linearity, recovery and stability for both of the analytes [18]. DBS sampling technique was selected because it enables the serial sampling from the same animal and offers improved data quality without changing the hemodynamic balance of the rodents [19]. The calibration curves were reliable, reproducible and linear for concentration range of $0.25-200 \mathrm{ng} / \mathrm{ml}$ during 5-days' validation period and the regression coefficient were always greater than 0.99 for both the analytes. The accuracy and precision for quality control samples were always within the acceptable limits of $\leq 20 \%$ for LLOQ and $\leq 15 \%$ for low, medium and high concentrations of the analytes.

\section{Pharmacokinetic interaction study}

The study animals tolerated the treatment as no peculiarities in the animals' behavior were observed for both centchroman only and losartan concomitant group. The concentration time profile and pharmacokinetic parameters obtained for centchroman with or without coadministration of losartan are shown in Figure 1 and Table 2, respectively. The blood concentration-time profile of 7-DMC was highly irregular and variable, therefore, the pharmacokinetic parameters of 7-DMC were not calculated. As shown in Figure 1, centchroman was detected up to $168 \mathrm{~h}$ after a single oral dose of $1.5 \mathrm{mg} / \mathrm{kg}$ in both the group of rats. In centchroman 


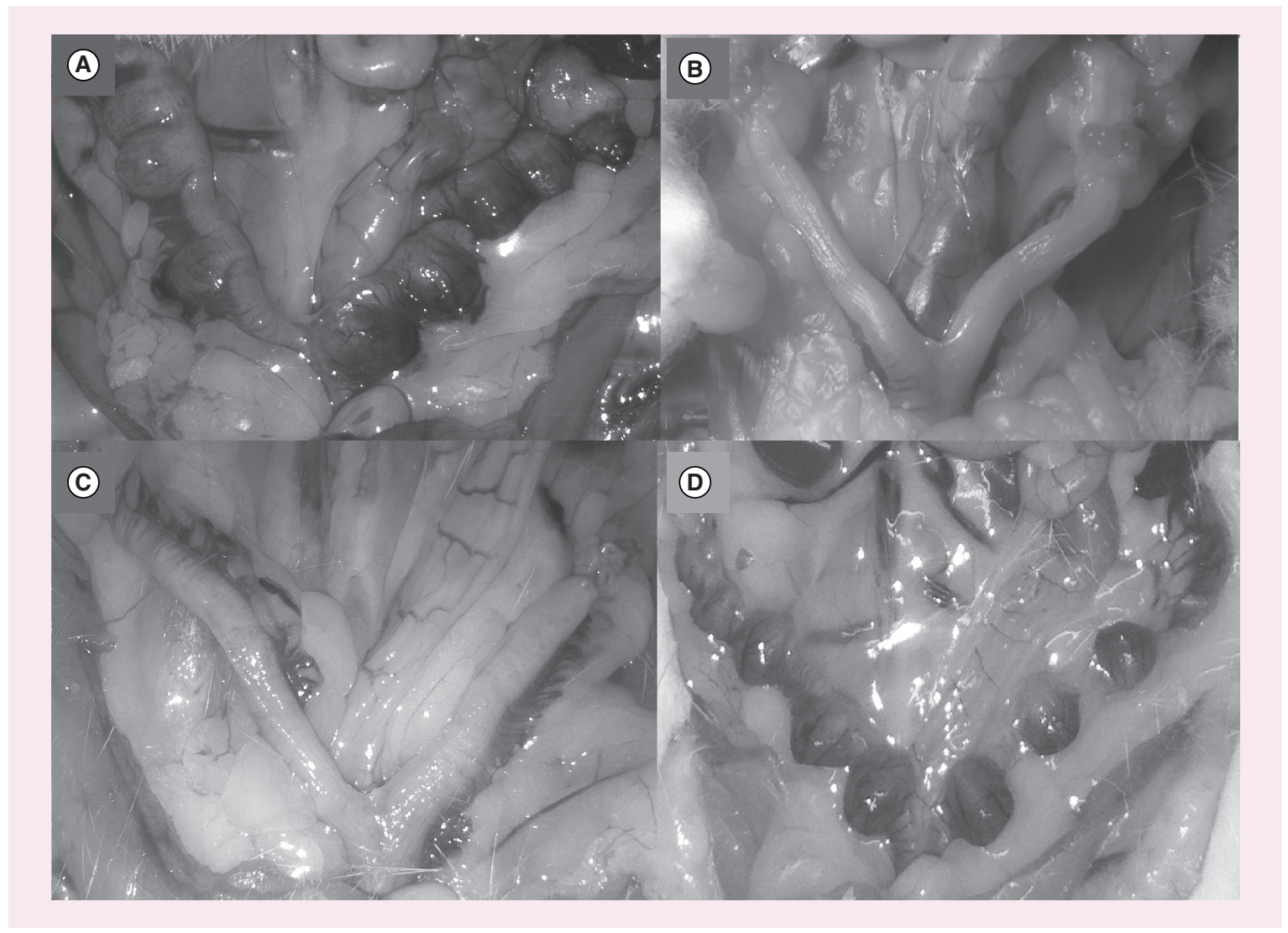

Figure 2. Typical lower abdomen image on day 10 postcoitum of sperm-positive female rats treated with (A) vehicle only, (B) centchroman only, (C) centchroman with losartan and (D) losartan only.

alone rats, the $\mathrm{V}_{\mathrm{d}} / \mathrm{F}$ and $\mathrm{Cl} / \mathrm{F}$ were calculated to be 18.7 $1 / \mathrm{kg}$ and $0.57 \mathrm{l} / \mathrm{h} / \mathrm{kg}$, respectively. The appearance of double peak of centchroman, rate of elimination and $\mathrm{t}_{1 / 2}$ were comparable, whereas the AUC, $\mathrm{Cl} / \mathrm{F}, \mathrm{V}_{\mathrm{d}} / \mathrm{F}$ and MRT were comparatively higher with those reported earlier [20,21]. This could be due to monitoring of the drug for a longer period. By visual inspection of the concentration time profile, it is clear that absorption of centchroman was not altered by co-administration of losartan. Also, a significant difference was observed in $\mathrm{C}_{\max }$ and $\mathrm{t}_{\max }$ of centchroman in rats treated with centchroman alone and with losartan. Multiple peak phenomenon of centchroman was not evident in losartan dosed group of rats. Values of AUC and MRT were reduced by 58.7 and $37.2 \%$, respectively, whereas $\mathrm{Cl} / \mathrm{F}$ was increased (2.5-fold) than the values obtained after centchroman dosing alone (Table 2). On co-administration of losartan, the relative bioavailability of centchroman was reduced to $41.3 \%$ which clearly indicates that losartan significantly affects the pharmacokinetic profile of centchroman in rats.

\section{Pharmacodynamic interaction study}

Adequate numbers of corpora lutea were observed in all the four study group of rats, which are representing the corpora of successive and normal ovulation cycles. As shown in Table 1, sperm-positive female rats of groups $\mathrm{B}$ and $\mathrm{C}$ did not exhibit any implantation (Figure 2) confirming the efficacy of the centchroman as well as the absence of any interaction between centchroman and losartan. However, the sperm-positive female rats administered vehicle only (groups A) and losartan only (groups D) showed normal implantations.

\section{Discussion}

Drug-drug interactions are the main advent of adverse drug reactions (ADR) with a share of $3-26 \%$ of total ADR events as well as in drug-related morbidity and mortality, which costs US $\$ 177.4$ dollar in the USA in 2000 [22]. The prevalence rate of drug-drug interactions is reported to be higher in adult patients than any other population age groups because other populations like pediatric patients are carefully monitored while prescribing the medicines [23]. Multiple peak phenomenon of centchroman was not evident in losartan-dosed group of rats. In the backdrop of experimental results, it appears that even though both losartan and centchroman have high plasma protein binding, losartan may be having preferential binding to plasma protein than centchroman resulting in higher systemic levels of centchroman. 
Table 2. Pharmacokinetic parameters of centchroman with and without co-administration of losartan in female Sprague Dawley rats.

\begin{tabular}{|c|c|c|c|}
\hline \multicolumn{2}{|l|}{ Parameters } & Centchroman & Centchroman + losartan \\
\hline \multirow[t]{2}{*}{$C_{\max }(\mathrm{ng} / \mathrm{ml})$} & 1 & $30.5 \pm 1.7$ & $35.2 \pm 7.9$ \\
\hline & 2 & $34.9 \pm 2.5$ & - \\
\hline \multirow[t]{2}{*}{$t_{\max }(h)$} & 1 & $4.8 \pm 0.9$ & $6.67 \pm 0.7$ \\
\hline & 2 & $44.4 \pm 11.8$ & - \\
\hline \multicolumn{2}{|l|}{$A \cup C_{\text {last }}(\mathrm{ng} \mathrm{h} / \mathrm{ml})$} & $2866.4 \pm 43.3$ & $1182.7 \pm 181.2^{\dagger}$ \\
\hline \multicolumn{2}{|l|}{$t_{1 / 2}(h)$} & $26.5 \pm 2.2$ & $29.3 \pm 0.8$ \\
\hline \multicolumn{2}{|l|}{$V_{d} / F(1 / k g)$} & $18.7 \pm 1.6$ & $55 \pm 9.9^{\dagger}$ \\
\hline \multicolumn{2}{|l|}{$\mathrm{Cl} / \mathrm{F}(\mathrm{l} / \mathrm{h} / \mathrm{kg})$} & $0.52 \pm 0.01$ & $1.3 \pm 0.2^{\dagger}$ \\
\hline \multicolumn{2}{|l|}{ MRT } & $68.9 \pm 7.6$ & $43.3 \pm 0.4^{\dagger}$ \\
\hline \multicolumn{4}{|c|}{$\begin{array}{l}{ }^{t} p<0.05 . \\
\text { Values of pharmacokinetic parameters are mean } \pm S E M(n=4) \text {. } \\
\text { AUC } C_{\text {last }}: \text { Area under the blood concentration-time curve up to } 168 \mathrm{~h} ; \mathrm{Cl} / \mathrm{F} \text { : clearance; } \mathrm{C}_{\max }: \text { Blood peak concentration; MRT: Mean residence } \\
\text { time; } \mathrm{t}_{\max } \text { : Time to } C_{\max } ; t_{1 / 2}: \text { Elimination half-life; } V_{\mathrm{d}} / \mathrm{F}: \text { Volume of distribution. }\end{array}$} \\
\hline
\end{tabular}

This makes centchroman available for metabolic clearance leading to lower AUC, higher clearance and volume of distribution. However, other pharmacokinetic parameters like $\mathrm{C}_{\max }, \mathrm{t}_{\max }$ and $\mathrm{t}_{1 / 2}$ were insignificantly altered in centchroman plus losartan dosing group of rats. After finding the positive sign of possible pharmacokinetic drug-drug interaction between centchroman and losartan, it was circumvented to embed the effect of losartan on the contraceptive efficacy of centchroman, but the pharmacodynamic results corroborate the scope of drug interaction that the losartan does not affect the contraceptive efficacy of centchroman to such extent that it may lead to contraception failure. A multiple dose interaction study is also required for further investigation of the likely changes in contraceptive efficacy due to altered pharmacokinetics of centchroman in losartan concomitant group of rats.

\section{Future perspective}

Drug-drug interactions are quite painful, when these are leading to contraception failure and result in unwanted pregnancy or abortion and create inevitable social, physical, emotional and/or economic burden to the childbearing age females. Most often these drugdrug interactions are undetectable. Although animals are not good model for studying pharmacokinetic drug-drug interactions, still, in addition of pharmacodynamic studies, they can provide scientific evidences and reveal the impending drug interaction possibilities. Further for clarifying the issue, these can be evaluated clinically.

\section{Conclusion}

Contraception failure, due to drug-drug interactions is the major cause of unwanted pregnancies and abortions. In our investigation, we studied the pharmacokinetic and pharmacodynamic interaction between the centchroman and losartan. A dried blood spot assisted LC-MS/MS method was fully validated and applied to interaction study of centchroman with losartan. The compiled results of the present pharmacokinetic and pharmacodynamic interaction studies in female rats evidenced that losartan did not alter the contraceptive efficacy of centchroman.

Executive summary

- In view of long-term concurrent clinical use of centchroman and losartan, we studied the pharmacokinetic and pharmacodynamic interaction between the centchroman and losartan.

- A dried blood spot assisted LC-MS/MS method was validated and applied to interaction study of centchroman with losartan.

- The sperm-positive female rats treated with centchroman alone and centchroman with losartan were investigated for the status of implantations and corpora lutea.

- The combined PK-PD results evidenced that losartan co-administration does not affect the pharmacodynamic profile or postcoital contraceptive efficacy of centchroman. 
Financial \& competing interests disclosure Abhisheak Sharma is thankful to Indian Council of Medical Research [grant number 45/57/2010-PHA/BMS], New Delhi, India, for financial support in the form of his fellowship for the CDRI Communication (9238). The authors have no other relevant affiliations or financial involvement with any organization or entity with a financial interest in or financial conflict with the subject matter or materials discussed in the manuscript apart from those disclosed. No writing assistance was utilized in the production of this manuscript.

\section{References}

Papers of special note have been highlighted as:

- of interest; $\bullet \bullet$ of considerable interest

1 Friedrichs E. On the pill. Nat. Med. 16(5), 506-508 (2010).

2 Lal J. Clinical pharmacokinetics and interaction of centchroman-A mini review. Contraception 81(4), 275-280 (2010).

-. Gives the details on discovery, mechanism of action, pharmacokinetics and uses of centchroman.

3 Maher DM, Khan S, Nordquist JL et al. Ormeloxifene efficiently inhibits ovarian cancer growth. Cancer Lett. 356(2 Pt B), 606-612 (2014).

4 Shahab SF, Jain S, Jain J, Jain U. Ormeloxifene: boon to perimenopausal dysfunctional uterine bleeding (DUB) women in avoiding hysterectomies. Int. J. Med. Sci. Education 1(1), 21-29 (2014).

5 Tejwani PL, Nerkar H, Dhar A et al. Regression of fibroadenomas with centchroman: a randomized controlled trial. Indian J. Surg. 77(2), 484-489 (2015).

6 Kumar S, Rai R, Agarwal G, Dwivedi V, Kumar S, Das V. A randomized, double-blind, placebo-controlled trial of ormeloxifene in breast pain and nodularity. Natl Med. J. India 26(2), 69-74 (2013).

7 Lal J, Nityanand S, Asthana O, Gupta R. Comparative bioavailability of two commercial centchroman tablets in healthy female subjects. Indian J. Pharmacol. 28(1), 32 (1996).

8 Ratna S, Roy S, Ray S et al. Centchroman: in vitro metabolism by rat liver homogenate. Drug Dev. Res. 7(2), 173-178 (1986).

9 Lal J, Nitynand S, Asthana OP, Nagaraja NV, Gupta RC. Optimization of contraceptive dosage regimen of Centchroman. Contraception 63(1), 47-51 (2001).

10 Koura MR, Al-Dabal BK, Rasheed P, Al-Sowielem LS, Makki SM. Prehypertension among young adult females in Dammam, Saudi Arabia. East. Mediterr. Health J. 18(7), 728-734 (2012).

11 Chaudhry K, Diwan SK, Mahajan SN. Prehypertension in young females, where do they stand? Indian Heart J. 64(3), 280-283 (2012).

12 Mohammed S. UK under pressure: A national study of blood pressure by Lloyds pharmacy (2010). www.dabl.ie/ pdf_articles/Lloyds_pharmacy_Blood_Pressure_Report_ July_2010.pdf

13 Conlin PR, Gerth WC, Fox J, Roehm JB, Boccuzzi SJ. Four-Year persistence patterns among patients initiating

\section{Ethical conduct of research}

The authors state that they have obtained appropriate institutional review board approval or have followed the principles outlined in the Declaration of Helsinki for all human or animal experimental investigations. In addition, for investigations involving human subjects, informed consent has been obtained from the participants involved.

therapy with the angiotensin II receptor antagonist losartan versus other artihypertensive drug classes. Clin. Ther. 23(12), 1999-2010 (2001).

14 Dahlof B, Devereux RB, Kjeldsen SE et al. Cardiovascular morbidity and mortality in the Losartan Intervention For Endpoint reduction in hypertension study (LIFE): a randomised trial against atenolol. Lancet 359(9311), 995-1003 (2002).

15 Sica DA, Gehr TW, Ghosh S. Clinical pharmacokinetics of losartan. Clin. Pharmacokinet. 44(8), 797-814 (2005).

-. Gives the details on discovery, mechanism of action, pharmacokinetics and uses of losartan.

16 Ray S, Grover PK, Anand N. New synthesis of cis- and trans-3- phenyl-4-[4-(h-pyrolidinoethoxy) phenyl]-7methoxy chromans. Indian J. Chem. 9, 727-728 (1971).

17 Freireich EJ, Gehan EA, Rall DP, Schmidt LH, Skipper HE. Quantitative comparison of toxicity of anticancer agents in mouse, rat, hamster, dog, monkey, and man. Cancer Chemother. Rep. 50(4), 219-244 (1966).

18 FDA. Guidance for industry: Bioanalytical method validation (2001). www.fda.gov/downloads/Drugs/ Guidances/ucm070107.pdf

-. Illustrates the current US FDA and pharmaceutical industry view on validation of bioanalytical methods.

19 Sharma A, Jaiswal S, Shukla M, Lal J. Dried blood spots: Concepts, present status, and future perspectives in bioanalysis. Drug Test. Anal. 6(5), 399-414 (2014).

- The details associated with dried blood spot method as an application of blood sampling are described.

20 Lal J, Sharma N. Simultaneous quantification of centchroman and its 7-demethylated metabolite in rat dried blood spot samples using LC-MS/MS. Biomed. Chromatogr. 26(9), 1089-1095 (2012).

-• Gives an account on the LC-MS/MS available for quantification of centchroman in dried blood spots.

21 Lal J, Paliwal JK, Grover PK, Gupta RC. Simultaneous liquid chromatographic determination of centchroman and its 7-demethylated metabolite in serum and milk. J. Chromatogr. B Biomed. Appl. 658(1), 193-197 (1994).

22 Ernst FR, Grizzle AJ. Drug-related morbidity and mortality: updating the cost-of-illness model. J. Am. Pharm. Assoc. 41(2), 192-199 (2001).

23 Dechanont S, Maphanta S, Butthum B, Kongkaew C. Hospital admissions/visits associated with drug-drug interactions: a systematic review and meta-analysis. Pharmacoepidemiol. Drug Saf. 23(5), 489-497 (2014). 
